\title{
CYSTIC ANGIOMATOSIS OF BONE
}

\section{A Report of Three Cases and Review of the Literature}

\author{
W. J. Boyle, Liverpool, England
}

From the Department of Orthopaedic Surgery, University of Liverpool

Cystic angiomatosis is the term which has become generally accepted to describe a rare condition in which multiple cystic lesions are scattered diffusely throughout the skeleton and are often associated with similar angiomatous changes in other tissues, notably the spleen.

Review of the twelve previously recorded cases in the English language literature reveals a marked similarity in radiological appearance, permitting a firm diagnosis from examination of the radiographs alone. The pathological feature common to all cases is a cystic lesion of blood vessel, of lymphatics or of mixed origin. The range of affection is from a relatively mild form in which the abnormality appears confined to the skeleton, to a severe variety in which there is widespread extra-skeletal involvement leading to early death.

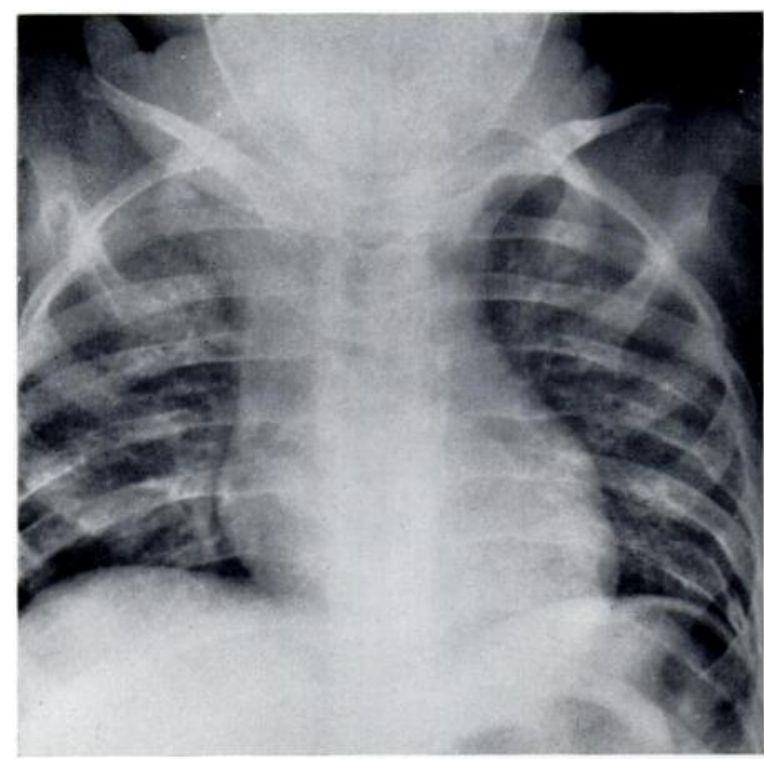

FIG. 1

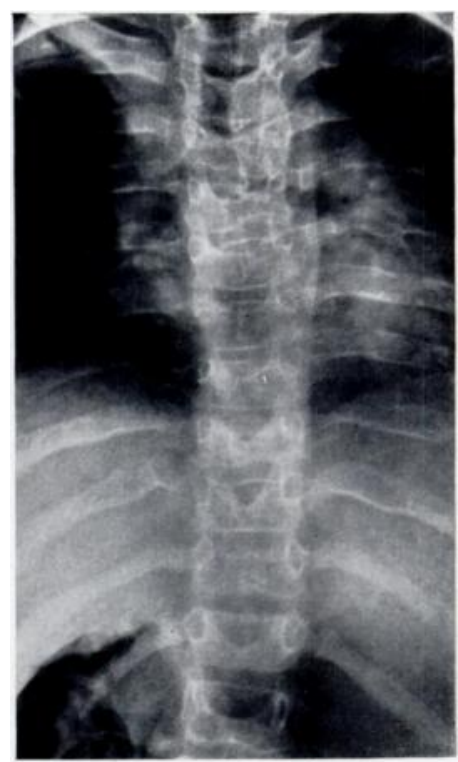

FIG. 2

Case 1-Multiple cystic areas scattered diffusely throughout the ribs.

The present three cases illustrate the typical radiographic and pathological appearances and demonstrate the wide variation in severity seen in this condition. In the first case there was an early presentation and a rapid progression to death. In the second case presentation was at puberty, and the lesion remained confined to the skeleton, producing only mild disability. The third patient was first seen in childhood and has been followed for nine years: recent radiographs suggest that the cystic lesions in the bones are regressing.

\section{CASE REPORTS}

Case 1-In February 1966, from a trivial fall, a boy aged two and a half years sustained a subtrochanteric fracture of the right femur through a cystic lesion. From the age of one year 
he had had intermittent, copious, blood-stained rhinorrhoea and since birth had been noted to have a soft bluish swelling below, behind and in front of the right ear. Skeletal survey revealed widespread cystic changes (Figs. 1 to 5). Lesions were present in skull, ribs, spine, pelvis, femora, humeri, left radius and left scapula.

The fracture was treated by fixation with a ' $V$ ' nail. The lesion through which the bone had broken was an 'empty cyst'. Histological examination of the bone showed only "cystic degeneration of the same family as fibrous dysplasia".

During the year after his discharge from hospital the child suffered intermittent attacks of pyrexia lasting for two to four days every four or five weeks. He was readmitted, but the results of all investigations were again normal. While the boy was in hospital his condition deteriorated and he died early in 1968.

Necropsy revealed lymphangiomatosis of the right cervical region, right pharyngeal wall and posterior wall of the thorax, with bilateral chylothorax and lymphangioma of the spleen.

Case 2-A boy aged thirteen years was observed on routine examination at school in 1968 to have marked upper thoracic kyphosis (Fig. 6). For some years previously he had had intermittent pain in his back when engaged in sports such as rugby football. At the time of examination he was still able to play football and com-

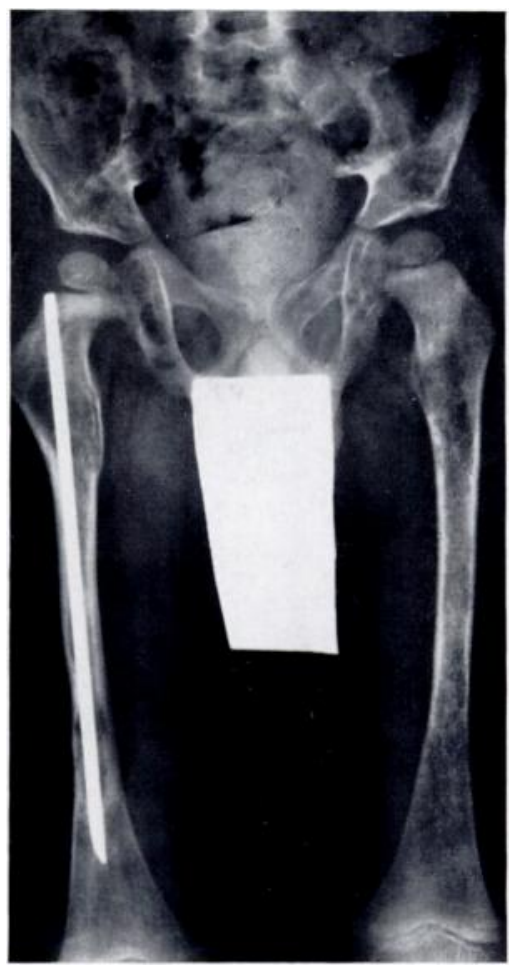

Fig. 3

Case $1-$ Cystic areas of bone destruction are present in the pelvis, particularly the pubic and ischial rami, and in both femora. A pathological fracture of the right femur has been fixed with a nail.

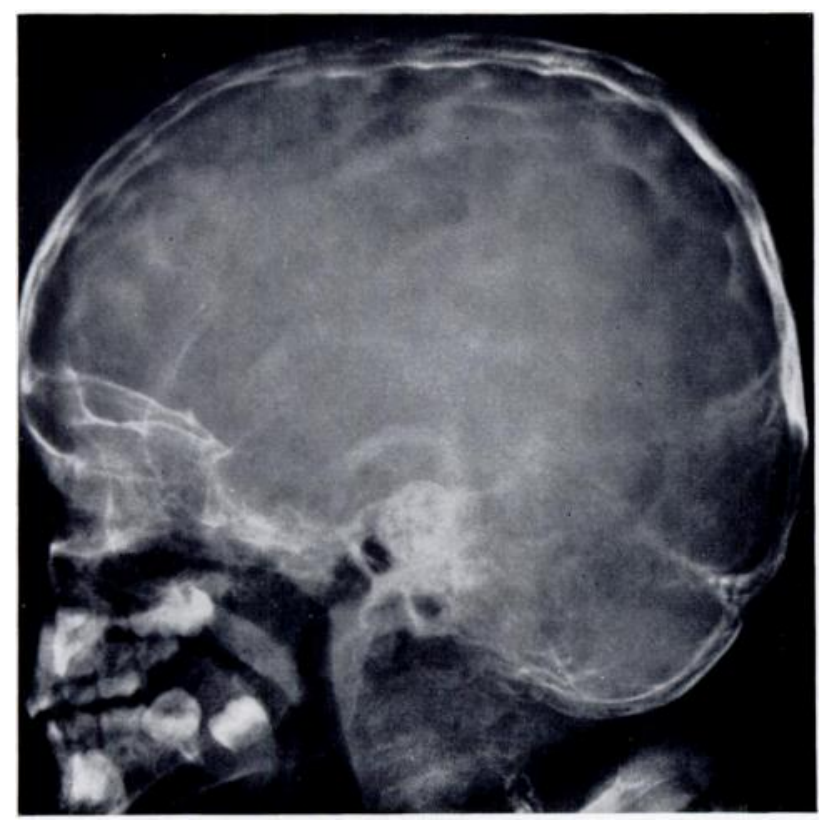

FIG. 4
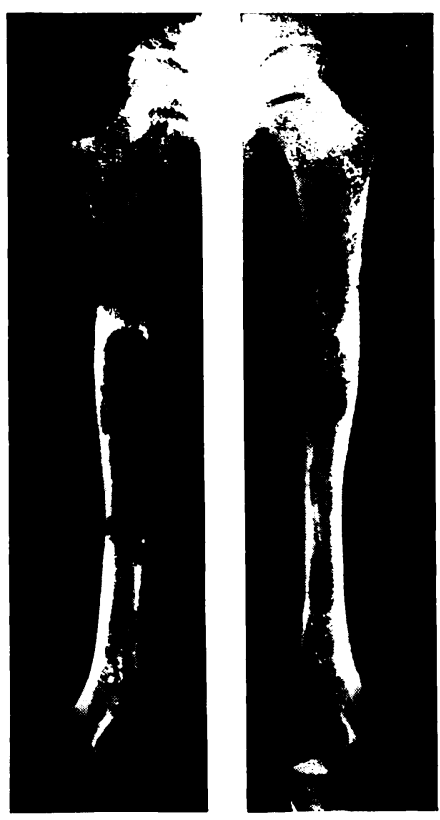

Fig. 5

Case 1. Figure 4-Radiograph showing osteoporosis with compression of the cervical vertebral bodies. Figure 5-Cystic lesions are present in the left and right humeri.

VOL. 54 B, NO. 4, NOVEMBER 1972 
plained of only occasional pain after the game. The parents thought that the deformity had first become apparent two or three years previously.

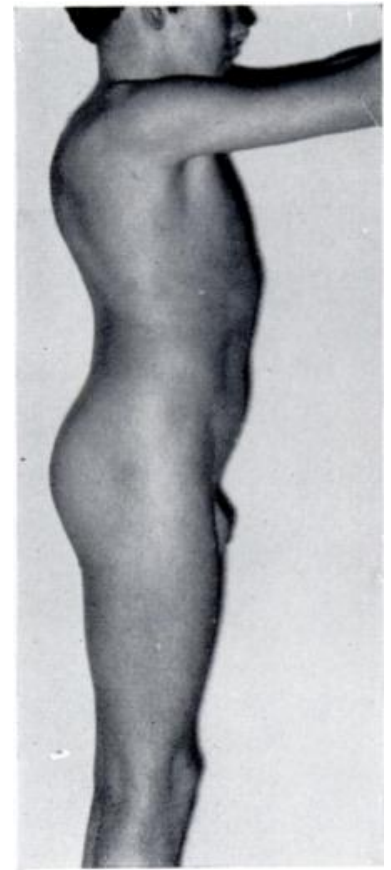

FIG. 6

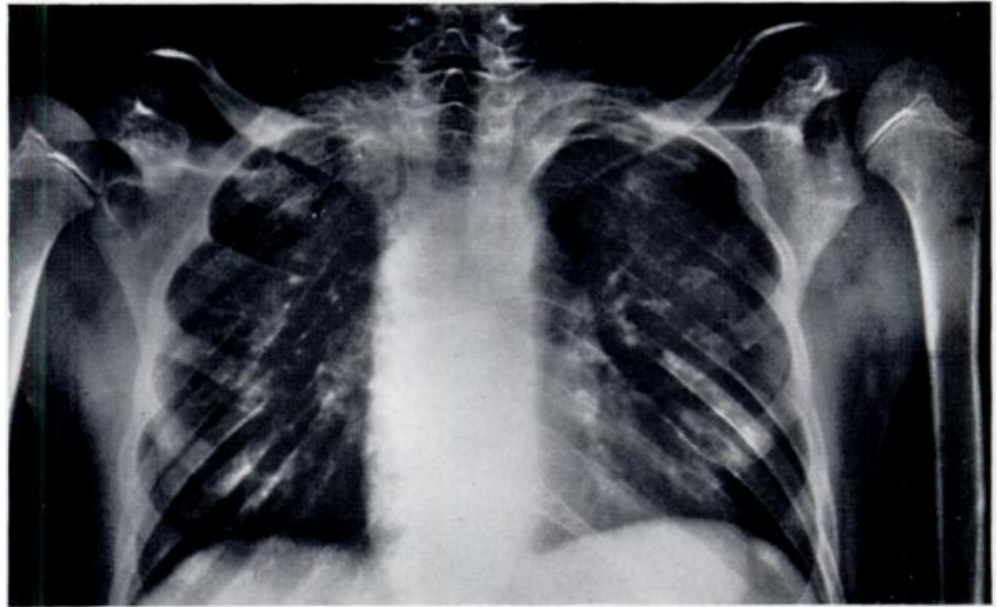

FIG. 7

Figs. 6 AND 7

Case 2. Figure 6-Appearance at initial presentation. Figure 7-Radiograph showing multiple cystic lesions scattered diffusely throughout the ribs. Lesions are also present in the neck of left humerus, head of right humerus and the glenoid and neck of left scapula.

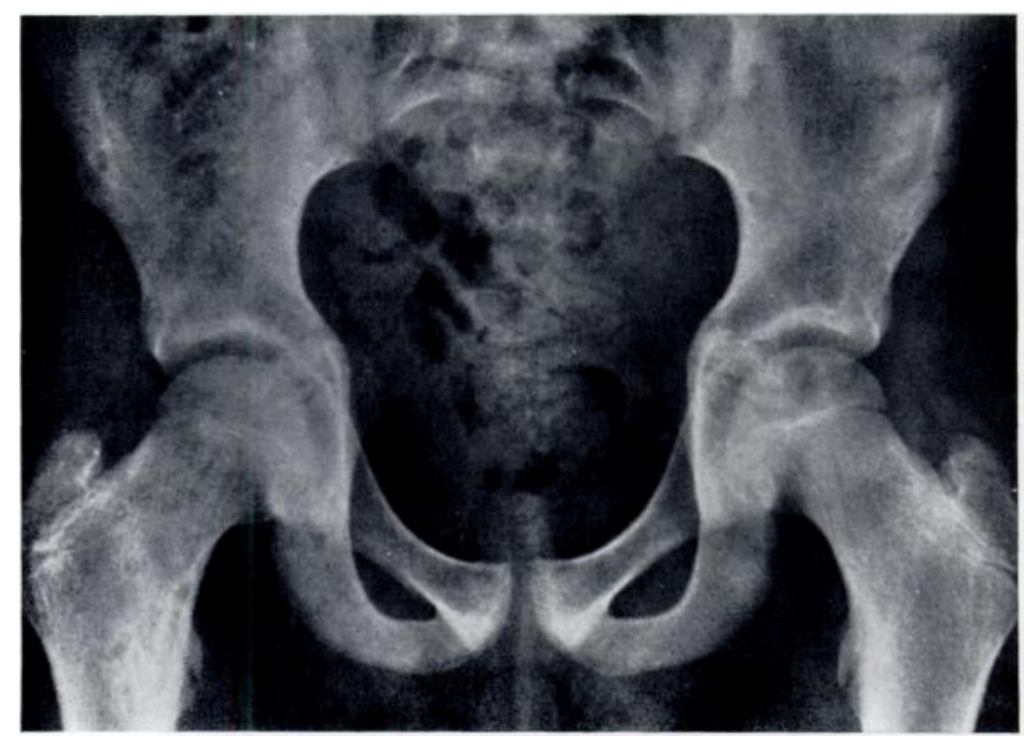

FIG. 8

Case 2-Cystic lesions in the capital epiphysis of the left femur, the neck of the right femur and right ischial and pubic rami.

The boy had a rather short trunk with a high thoracic kyphosis and thoraco-lumbar lordosis. The only other clinical abnormality was a large number of pigmented moles present mainly in the chest area. There were no abnormal neurological signs. 
The results of all investigations of the blood and urine were normal. A skeletal survey showed widespread cystic lesions involving the thoracic spine, ribs, left humerus, scapula, pelvis, proximal ends of both femora and the vault of the skull (Figs. 7 to 10).

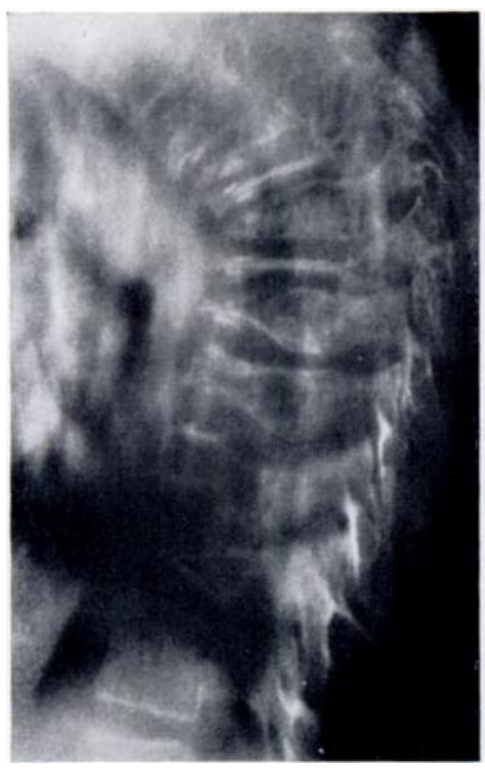

Fig. 9

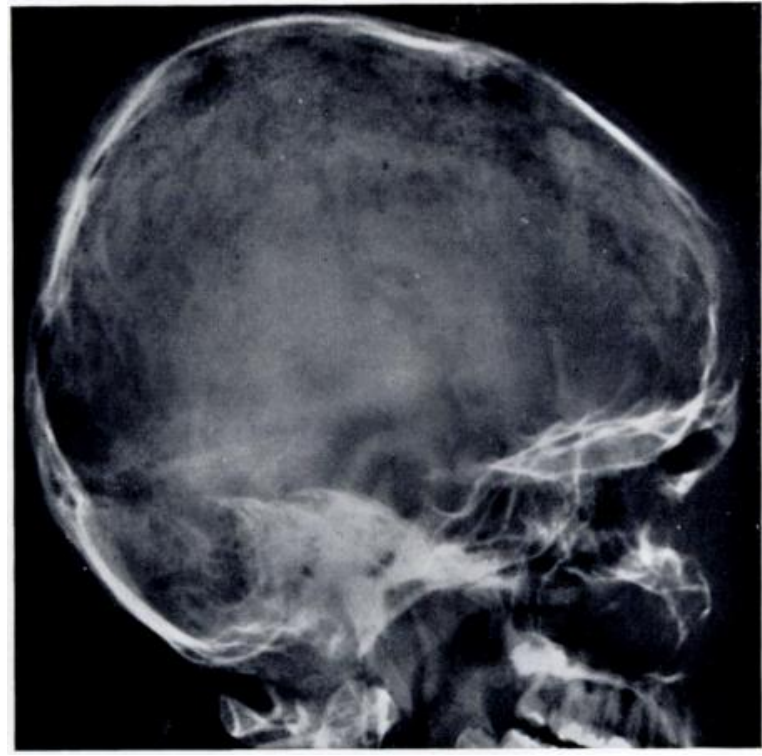

Fig. 10

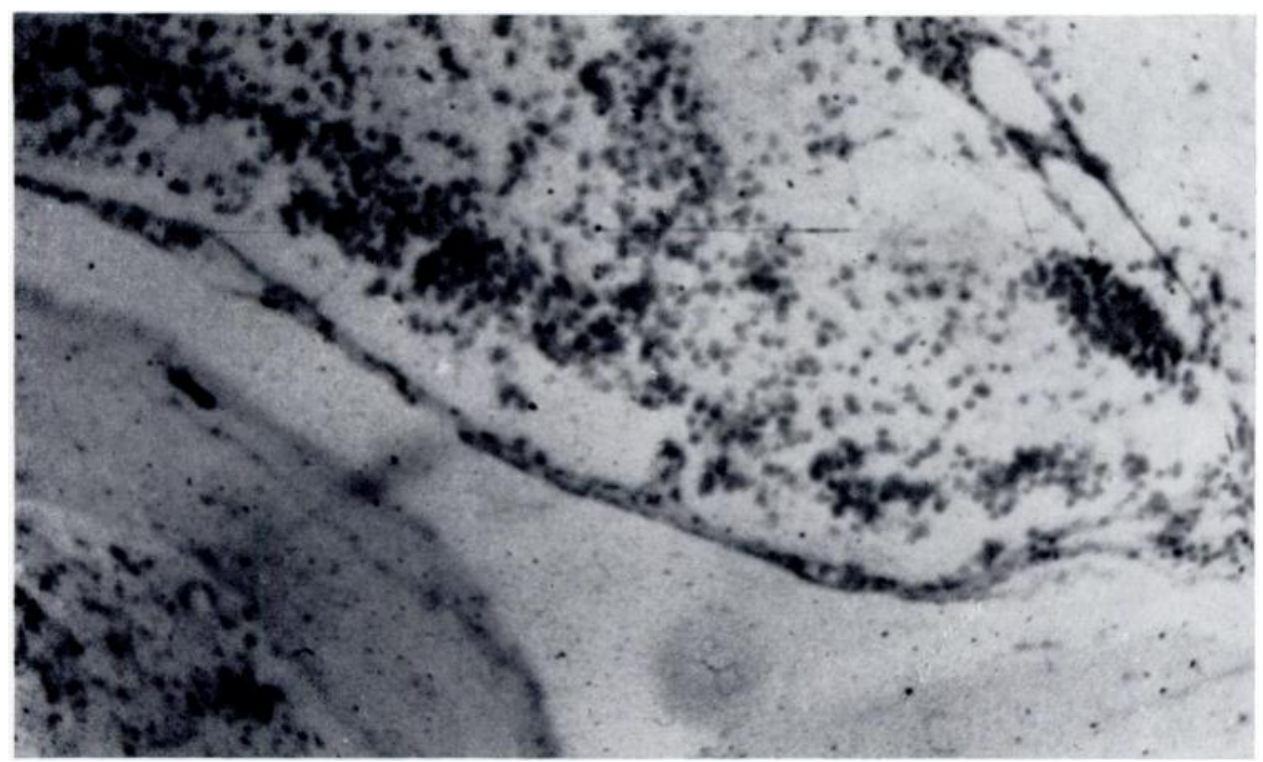

Fig. 11

Case 2. Figure 9-Radiograph of thoracic spine showing collapse of several vertebral bodies with persistence of the ring epiphyses giving a "Calvé" appearance. Figure 10-Several areas of osteolysis are shown in the parietal and frontal regions. Figure 11-Photomicrograph showing bony trabeculum with single layer of endothelial cells forming part of the wall of a cyst packed with red blood cells. $(\times 350$. $)$

Biopsy of the affected parts of the right tenth and eleventh ribs was done. The ribs were expanded by multiple cysts which had eroded the cortex to leave a thin translucent shell through which the contents appeared blue. The affected bone had a honeycomb texture, the 
cysts varying in size up to about half a centimetre in diameter. Histology revealed multiple cysts separated by thin bony trabeculae, lined by endothelial cells and packed with red blood cells, the appearance being that of cavernous haemangioma of bone (Fig. 11).

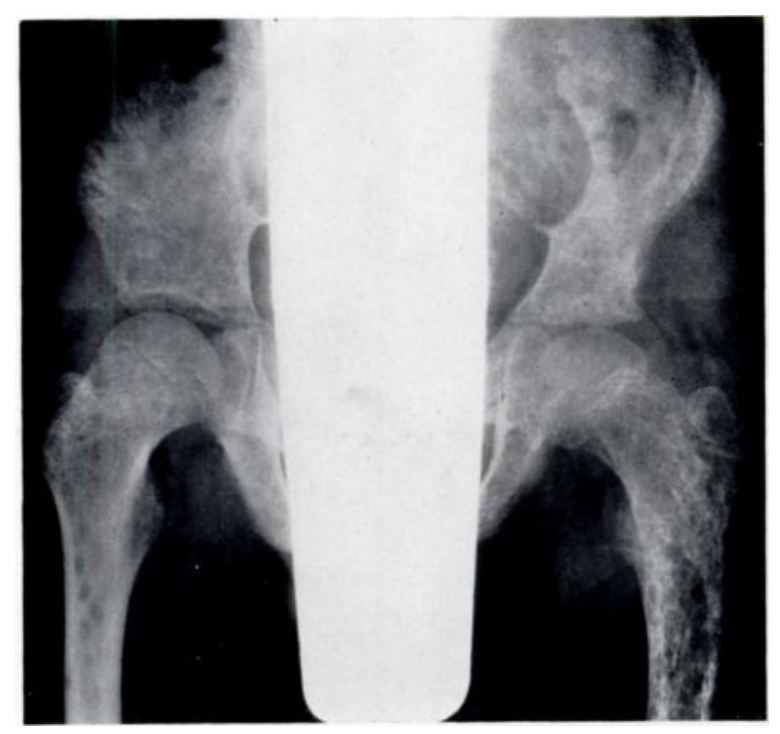

FIG. 12

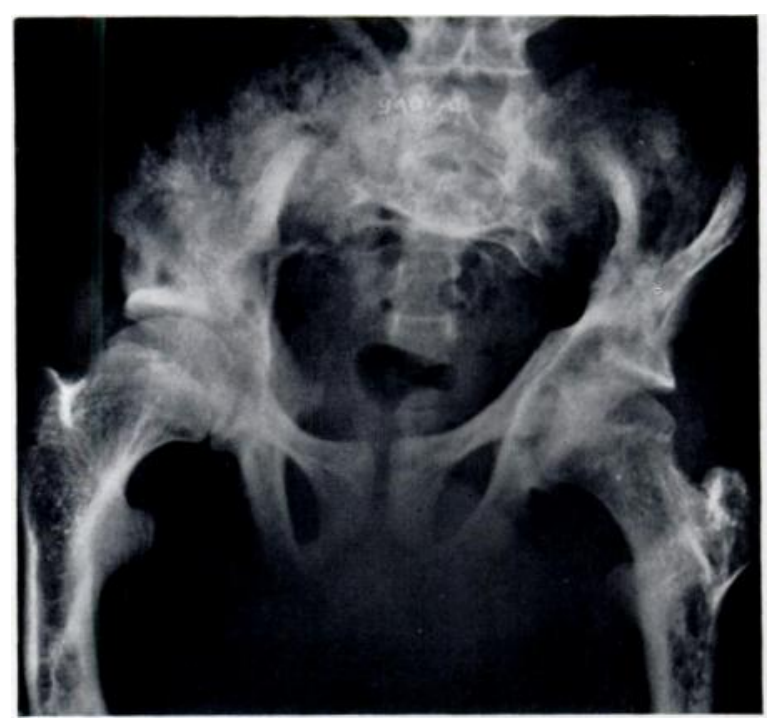

Fig. 13

Case 3. Figure 12-Appearances in 1964. Figure 13-Six years later: considerable radiological improvement with a reduction in the number of bone cysts in the pelvis and upper femora.

Case 3-A boy aged five years presented in 1961 with a swelling in the subcutaneous tissues of the left groin which was diagnosed as a haemangioma or possibly a cystic hygroma. In 1962 he developed a limp with painful limitation of movement of the left hip. Radiographs showed diffuse cystic changes throughout the pelvis and the whole of the right femur including the 
lower epiphysis, with less marked involvement of the right femur but again including the lower femoral epiphysis. Biopsy of the right iliac crest was carried out but no information of value was obtained. Skeletal survey showed diffuse involvement of the pelvis, femora, humeri, lumbar spine and ribs (Figs. 12 to 14). Less severe cystic changes were seen in both tibiae, clavicles and right radius. The skull was not affected but a lesion was present in the ascending ramus of the mandible.

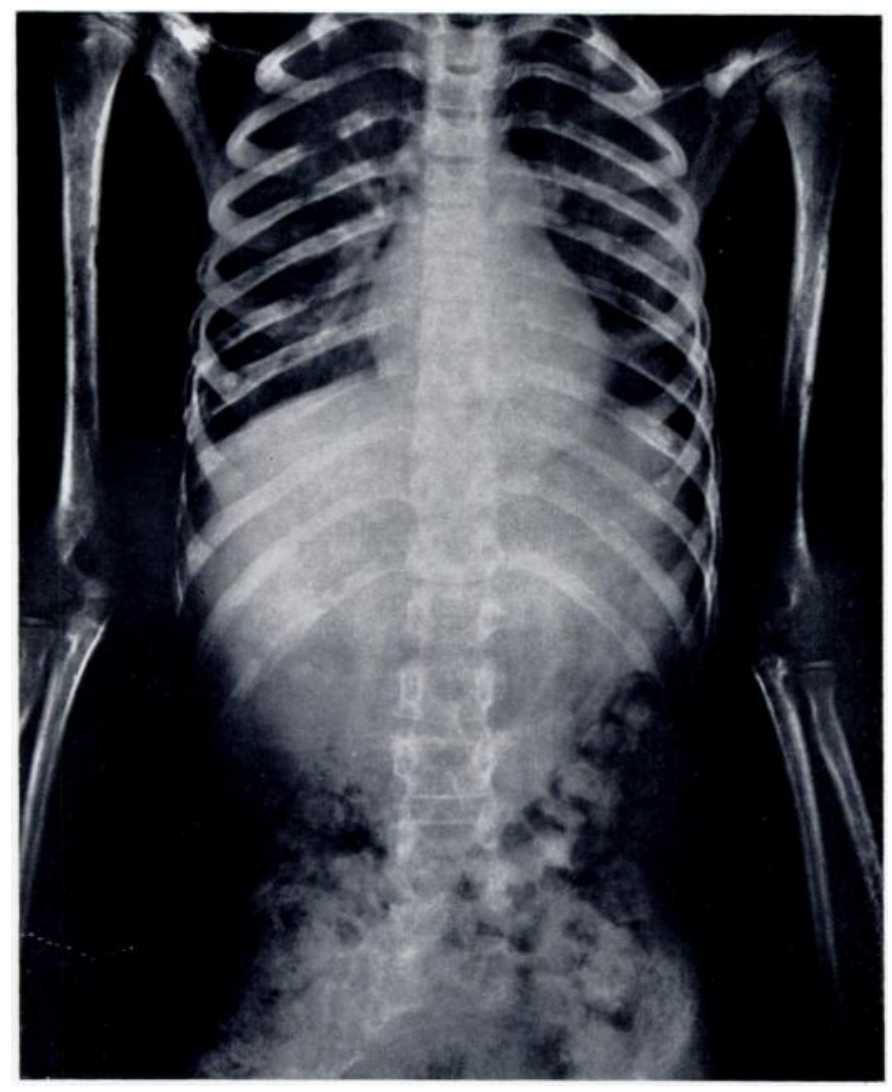

FIG. 14

Case 3-Radiograph showing multiple cystic lesions scattered diffusely throughout the ribs, both humeri, scapulae and pelvis.

In 1963 biopsy of the left iliac crest was carried out. The width of the ilium was seen to be increased and a marked irregular honeycombed trabeculation was noted. Bleeding was minimal. Microscopy showed widely separated trabeculae bounding cystic spaces containing a loose fibrinous coagulum. The appearance was compatible with lymphangiectasia.

In 1964 the child slipped and sustained a subtrochanteric fracture of the left femur. An attempt at internal fixation of the fracture was made but the bone was found to be too soft and operation was abandoned, the limb being supported in a Thomas's splint and subsequently in a weight-relieving caliper. In 1968 he fell again, sustaining a fracture at the junction of the middle and upper thirds of the right femur which was again treated in a Thomas's splint.

The boy has remained under observation and now walks without the aid of a caliper. The left leg is 2.5 centimetres shorter than the right. The cystic changes have become less extensive and the texture of the bone stronger, though multiple cysts are still present (Figs. 12 to 14$)$.

VOL. 54 B, NO. 4, NOVEMBER 1972 
TABLE I

Fifteen Recorded CASes of Cystic Angiomatosis

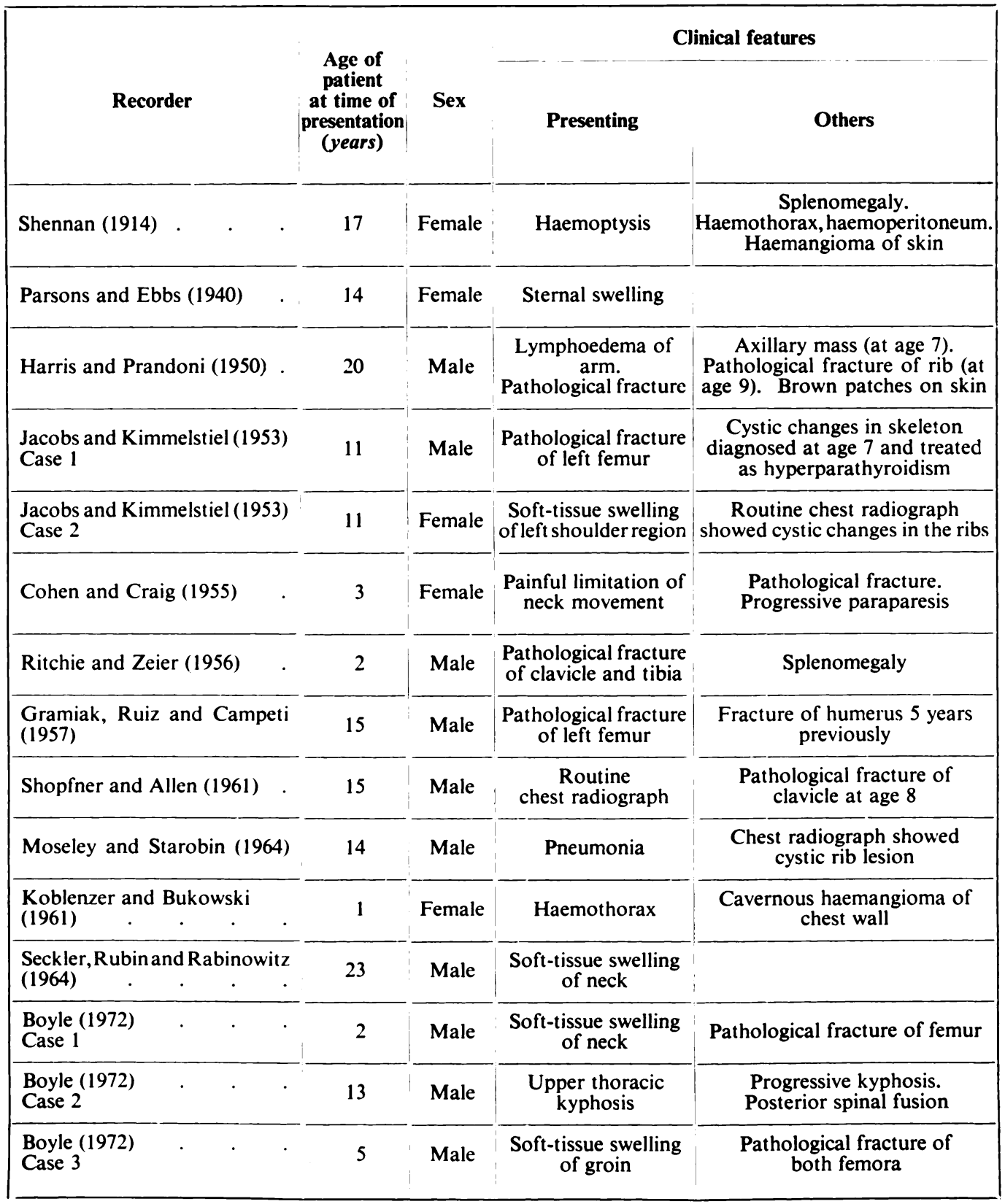

\section{CLINICAL FEATURES}

Consideration of the present cases in conjunction with those previously reported (Table I) shows that the usual modes of presentation are: 1) soft-tissue swelling; 2) incidental finding on chest radiograph; and 3) pathological fracture. Fracture occurred at some stage in over half the cases.

Only one patient has survived when extraskeletal lesions, other than those in skin and subcutaneous tissues, have been present. This was a boy aged two and a half years who had 
TABLE I-continued

Fifteen Recorded Cases of Cystic Angiomatosis

\begin{tabular}{|c|c|c|c|c|c|c|c|}
\hline \multicolumn{2}{|r|}{ Radiographic lesions } & \multicolumn{2}{|c|}{ Biopsy } & \multicolumn{2}{|c|}{ Tissues involved } & \multirow[b]{2}{*}{ Histology } & \multirow[b]{2}{*}{ Outcome } \\
\hline $\begin{array}{c}\text { Skull } \\
\text { Pelvis } \\
\text { Ribs } \\
\text { Femur }\end{array}$ & Other sites & Site & Result & $\begin{array}{l}\text { Bone } \\
\text { only }\end{array}$ & \begin{tabular}{|c|} 
Viscera \\
other than \\
skin and \\
subcutaneous \\
tissues
\end{tabular} & & \\
\hline & No radiographs & & & & $\div-$ & Lymphangioma & Died \\
\hline$-\phi$ & $\begin{array}{l}\text { Sternum, humeri, tibiae, } \\
\text { right fibula }\end{array}$ & Sternum & - & & + & Haemangioma & Died \\
\hline+ & $\begin{array}{l}\text { Right scapula, spine, } \\
\text { humerus, ulna, right tibia }\end{array}$ & Rib & + & & & Lymphangioma & \\
\hline+ & Humeri, scapulae & Ilium & $\overline{+}$ & + & $\mid$ & Lymphangioma & \\
\hline+ & $\begin{array}{l}\text { Humeri, radii, ulnae, } \\
\text { tibiae, scapulae }\end{array}$ & Rib & + & -4 & & Lymphangioma & \\
\hline$-f$ & Spine, humerus, clavicle & \begin{tabular}{|l} 
Ilium \\
Femur \\
Clavicle
\end{tabular} & $\begin{array}{l}- \\
- \\
-\end{array}$ & & $\therefore$ & Lymphangioma & Died \\
\hline tr & $\begin{array}{l}\text { Diffuse, except hands } \\
\text { and feet }\end{array}$ & $\begin{array}{l}\text { Tibia } \\
\text { Rib }\end{array}$ & 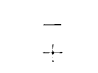 & & -4 & Haemangioma & \\
\hline+ & Spine, humeri, scapulae & $\begin{array}{c}\text { Skull } \\
\text { Rib }\end{array}$ & $\overline{+}$ & -+- & & Lymphangioma & \\
\hline except pelvis & $\begin{array}{l}\text { Skull, ribs, femora, } \\
\text { humeri, tibiae }\end{array}$ & Tibia & + & + & & Lymphangioma & \\
\hline+ & Spine, great toe & Rib & + & & & Haemangioma & \\
\hline+ & $\begin{array}{l}\text { Clavicles, scapula, } \\
\text { spine, tibiae }\end{array}$ & $\begin{array}{l}\text { Rib } \\
\text { Skin }\end{array}$ & - & & $-:-$ & Mixed & Died \\
\hline+ & Vertebrae & Rib & + & & & Lymphangioma & \\
\hline$\div$ & $\begin{array}{l}\text { Left radius, scapula, } \\
\text { vertebrae, humeri }\end{array}$ & Femur & - & & + & Lymphangioma & Died \\
\hline+ & Scapulae, humerus, spine & Rib & + & +- & & Haemangioma & \\
\hline except skull & $\begin{array}{l}\text { Spine, tibiae, humeri, radius, } \\
\text { clavicles, scapulae, mandible }\end{array}$ & $\begin{array}{l}\text { Ilium } \\
\text { Ilium }\end{array}$ & $\div$ & & & Lymphangioma & \\
\hline
\end{tabular}

severe splenomegaly (Ritchie and Zeier 1956). He was alive and well three years after removal of the spleen.

\section{RADIOLOGICAL FEATURES}

The radiological changes alone are usually characteristic enough to sustain the diagnosis. In all patients many bones have been involved and in nearly all cases the skull, ribs, pelvis and femora have been affected. The lesions tend to occur centrally rather than peripherally, in that

VOL. 54 B, NO. 4, NOVEMBER 1972 
the hands and feet are rarely involved and lesions in the forearm bones and tibia and fibula occur less frequently than do lesions in the humeri and femora. The scapulae were involved in ten of the fourteen cases and the clavicle in four. The spine is frequently involved and in Case 2 of the present series it was the principal area affected, progressive kyphosis being the presenting clinical feature (Fig. 6).

The radiological feature common to all cases is the presence of multiple cystic areas of bone destruction. The margins of the cystic areas are usually sharply defined by a sclerotic rim. Sometimes this dense rim is absent and rarely the edge of the lesion is not clearly demarcated and blends with the surrounding bone.

The lesions are usually round or oval in shape and situated in the medulla. They may, however, appear in the cortex which, especially in rib lesions, may be expanded and thinned from within but is never breached unless pathological fracture occurs; nor is there ever any periosteal reaction. The size of the lesion is variable and to some extent appears to be influenced by the space available, in that lesions in the ribs tend to be small whereas larger areas of bone destruction are found in the pelvis and long bones.

The vertical striations which are associated with haemangiomata of vertebral bodies are not seen in cystic angiomatosis. The lesions are usually round or oval as at other sites, but occasionally a "Calvé-like" appearance is seen: the vertebral body is reduced to a thin wafer with persistence of the ring epiphyses (Fig. 9).

\section{PATHOLOGY}

The fundamental lesion, whether in soft tissue or bone, is a cyst, which may be multilocular, lined by a single layer of endothelium and containing either red blood cells or a homogeneous pink-staining coagulum. The cysts represent dilated vascular channels which may be of blood vessel or lymphatic origin as indicated by their contents. In some descriptions it is apparent that both may be present in the same patient, suggesting that there is a basic malformation which may develop in either a haemangiomatous or lymphangiomatous direction.

\section{DISCUSSION}

Cystic angiomatosis of bone occurs twice as frequently in boys as in girls and half of the patients whose cases have been reported have presented at around the age of puberty (Table I), though the scatter is from one to twenty-three years.

It is most important on clinical examination to look for involvement of abdominal or thoracic organs, because in all reported fatal cases there have been visceral lesions, the spleen aliways being affected.

The diagnosis must be confirmed by removing an affected piece of bone and submitting it to histological examination. The most satisfactory specimen for this purpose is an involved rib: eight out of nine biopsies from this site have proved diagnostic whereas bone taken from ten out of twelve other sites has been found to be of no value.

In established cases there seems to be little that one can do to alter the prognosis. Radiotherapy and chemotherapy have been tried (Cohen and Craig 1955; Gramiak, Ruiz and Campeti 1957; Koblenzer and Bukowski 1961) and found to be ineffective. If the spleen is considered to be the only viscus involved it seems reasonable on the basis of the case reported by Ritchie and Zeier (1956) to remove it.

Pathologically cystic angiomatosis is now clearly defined, but its etiology remains obscure. There are two principal alternatives: 1) that it is a true neoplasm-a metastasising angioma; or 2) that it is a congenital malformation of multicentric origin-a vascular hamartoma.

In favour of neoplasm are the facts that the lesions are scattered diffusely throughout the skeleton and other tissues and that although they are always histologically benign they may behave malignantly. It has also been noted (Ritchie and Zeier) that the skeletal lesions may 
increase in number as well as in size. With regard to malignant disease in general, however, it is extremely rare for the spleen to be the site of secondary deposit, and yet it is always the first organ outside the skeleton to be involved in cystic angiomatosis. This would argue against the neoplastic view unless one postulated the unlikely possibility that the primary lesion was in the spleen.

Vascular hamartomata exhibit the phenomenon of delayed appearance (Willis 1958). Ninety-six per cent of angiomata of skin and subcutaneous tissue are visible at birth or appear within the first six months (Fitzwilliams 1911), whereas those of deeper tissues or viscera may not present until childhood or even adult life. The age distribution in relation to the site of the lesion would, therefore, be in keeping with this general pattern.

In the foetus there is a diffuse plexus of primitive vascular channels, some of which persist to form the adult vascular tree, the remainder disappearing. It is possible that rests of this primitive vascular tissue persist and form the basis for the later diffuse, multicentric appearance of the lesions in cystic angiomatosis. What factor is responsible for either the persistence or later cystic expansion of these rests can only be conjectured.

It is possible that there is a spectrum of angiomatous conditions from the single lesion in skin or subcutis to a wider involvement of the deeper limb tissues or viscera or nervous system and ultimately to a diffuse simultaneous involvement of many tissues, of which cystic angiomatosis of bone is one syndrome. This would be akin to the multivarious manifestations of the typically hamartomatous condition neurofibromatosis.

It has been suggested (Harris and Prandoni 1950) that cystic angiomatosis arises from a metaplasia of the reticulo-endothelial system and may thus be related to diseases such as Gaucher's or Histiocytosis "X". The "Calvé" appearance of which eosinophil granuloma is a known cause, seen in Case 2 of the present series, lends some radiological support to this hypothesis.

\section{DIFFERENTIAL DIAGNOSIS}

Histiocytosis $\mathbf{X}$-The skeletal distribution is similar in cystic angiomatosis and Histiocytosis $\mathbf{X}$. In the latter, however, the skull is involved five times more frequently than any other site and the "punched out lesions" do not usually have a peripheral ring of increased density but tend to coalesce to produce map-like areas of bone destruction. Lesions near the cortex of long bones stimulate a periosteal reaction, a feature never seen in angiomatosis.

Hyperparathyroidism-In hyperparathyroidism the cyst-like translucent areas are not usually demarcated sharply by a sclerotic rim, and although they may occur in virtually any bone they are rare in the vertebrae and vault of the skull. In the former, a coarse trabecular pattern is seen whereas in the latter a mottled appearance is characteristic. Cortical thinning and subperiosteal erosions occur particularly in the phalanges of the hand and in the mandible; the lamina dura and surrounding bone may be absorbed.

Polyostotic fibrous dysplasia-The lesions are surrounded by a much denser rim of bone than in cystic angiomatosis and in long bones are most commonly found in the middle third. They are sometimes trabeculated, especially in the larger lesions, and have an opalescent or ground glass background.

\section{SUMMARY}

1. Three cases of cystic angiomatosis of bone are presented and the literature is reviewed.

2. The typical radiological appearances are described and illustrated.

3. The diagnosis must be confirmed by biopsy, and it is essential that the bone removed should be from an involved rib.

4. The prognosis is dependent upon extraskeletal visceral involvement and is not influenced by radiotherapy or chemotherapy. Splenectomy may improve the chance of survival when the spleen is the only viscus involved.

I wish to thank Professor Robert Roaf and Mr E. M. Kupfer for allowing me access to their patients.

VOL. 54 B, NO. 4, NOVEMBER 1972 


\section{REFERENCES}

Cohen, J., and Craig, J. M. (1955): Multiple Lymphangiectases of Bone. Journal of Bone and Joint Surgery, 37-A, 585.

Fitzwilliams, D. C. L. (1911): The Etiology of Naevi: Nerve Influence in Their Causation. British Medical Journal, 9, 489.

Gramiak, R., Ruiz, G., and Campeti, F. L. (1957): Cystic Angiomatosis of Bone. Radiology, 69, 347.

Harris, R., and Prandoni, A. G. (1950): Generalized Primary Lymphangiomas of Bone: Report of Case Associated with Congenital Lymphedema of Forearm. Annals of Internal Medicine, 33, 1302.

JaCoBS, J. E., and Kimmelstiel, P. (1953): Cystic Angiomatosis of the Skeletal System. Journal of Bone and Joint Surgery, 35-A, 409.

Koblenzer, P. J., and Bukowski, M. J. (1961): Angiomatosis (Hamartomatous Hem-Lymphangiomatosis). Pediatrics, 28, 65.

Moseley, J. E., and Starobin, S. G. (1964): Cystic Angiomatosis of Bone: Manifestations of a Hamartomatous Disease Entity. American Journal of Roentgenology, Radium Therapy and Nuclear Medicine, 91, 1114.

Parsons, L. G., and EbBs, J. H. (1940): Generalized Angiomatosis Presenting the Clinical Characteristics of Storage Reticulosis. Archives of Diseases of Childhood, 15, 129.

Ritchie, G., and ZeIER, F. G. (1956): Hemangiomatosis of the Skeleton and the Spleen. Journal of Bone and Joint Surgery, 38-A, 115.

Seckler, S. G., Rubin, H., and Rabinowitz, J. G. (1964): Systemic Cystic Angiomatosis. American Journal of Medicine, 37, 976.

Shennan, T. (1914): Histologically Non-malignant Angioma, with Numerous Metastases. Journal of Pathology and Bacteriology, 19, 139.

Shopfner, C. E., and Allen, R. P. (1961): Lymphangioma of Bone. Radiology, 76, 449.

Willis, R. A. (1958): The Borderland of Embryology and Pathology. London: Butterworth and Company (Publishers) Limited. 